\title{
Gambaran Pelaksanaan Program Pencegahan dan Pengendalian Infeksi Di Rumah Sakit Umum X Kota Y
}

\author{
Mike Rismayanti ${ }^{1}$, Hardisman ${ }^{2}$
}

\begin{abstract}
Abstrak
Infeksi yang terjadi di rumah sakit disebut juga infeksi nosokomial atau Hospital Acquired Infections (HAl's) merupakan problem yang serius bagi kesehatan masyarakat. HAl's merupakan infeksi yang didapat pasien selama menjalani prosedur perawatan dan tindakan medis di pelayanan kesehatan setelah $\geq 48$ jam dan setelah $\leq 30$ hari setelah keluar dari fasilitas kesehatan. Berdasarkan sumber infeksi, maka infeksi dapat berasal dari masyarakat/komunitas (Community Acquired Infection) atau dari rumah sakit (Healthcare-Associated Infections/HAls). Tujuan penelitian ini adalah melihat gambaran umum pelaksanaan program pencegahan dan pengendalian infeksi di Rumah Sakit Umum X. Pencegahan dan Pengendalian Infeksi di Rumah Sakit (PPIRS) sangat penting karena menggambarkan mutu pelayanan rumah sakit juga untuk melindungi pasien, petugas, pengunjung dan keluarga dari resiko tertularnya infeksi. Infeksi yang terjadi di rumah sakit tidak saja dapat dikendalikan tetapi juga dapat dicegah dengan melakukan langkah-langkah yang sesuai dengan prosedur dan pedoman yang berlaku. Untuk meminimalkan resiko terjadinya infeksi di rumah sakit perlu diterapkan program Pencegahan dan Pengendalian Infeksi (PPI), yaitu kegiatan yang meliputi perencanaan, pelaksanaan, pembinaan, pendidikan, pelatihan, monitoring dan evaluasi.
\end{abstract}

Kata kunci: pencegahan dan pengendalian infeksi, HAl's, rumah sakit

\section{Abstract}

Infections that occur in hospitals are also called nosocomial infections or Hospital Acquired Infections (HAl's) is a serious problem for public health. $H A l$ is an infection that patients get during undergoing treatment procedures and medical procedures in health services after $\geq 48$ hours and after $\leq 30$ days after leaving a health facility. Based on the source of infection, the infection can come from the community/community (Community Acquired Infection) or from the hospital (Healthcare-Associated Infections/HAls). The objective of this study was to see an overview of the implementation of the infection prevention and control program at $X$ General Hospital. Infection prevention and control in hospitals (PPIRS) is very important because it describes the quality of hospital services also to protect patients, officers, visitors and families from the risk of infection. Infections that occur in hospitals can not only be controlled but can also be prevented by taking steps that are in accordance with the procedures and guidelines that apply. To minimize the risk of infection in a hospital, it is necessary to implement an Infection Prevention and Control (PPI) program, an activity that includes planning, implementation, guidance, education, training, monitoring and evaluation.

Keywords: infection prevention and control, HAl's, hospital

Affiliasi penulis: 1. Dinas Kesehatan Kabupaten Solok, 2. Bagian Kesehatan Masyarakat Fakultas Kedokteran Universitas Andalas Padang,

Korespondensi: Mike Rismayanti, Email mikebennyalya@gmail.com Telp: 085264129343

\section{PENDAHULUAN}

Infeksi yang terjadi di rumah sakit disebut juga infeksi nosokomial atau Hospital Acquired Infections
(HAl's) merupakan problem yang serius bagi kesehatan masyarakat. HAl's merupakan infeksi yang didapat pasien selama menjalani prosedur perawatan dan tindakan medis di pelayanan kesehatan setelah $\geq$ 48 jam dan setelah $\leq 30$ hari setelah keluar dari fasilitas kesehatan. ${ }^{1}$

Berdasarkan sumber infeksi, maka infeksi dapat berasal dari masyarakat/komunitas (Community 
Acquired Infection) atau dari rumah sakit (HealthcareAssociated Infections/HAls). HAls (HealthcareAssociated Infections) dengan pengertian yang lebih luas, yaitukejadian infeksi tidak hanya berasal dari rumah sakit, tetapi juga dapat dari fasilitas pelayanan kesehatan lainnya. Tidak terbatas infeksi kepada pasien namun dapat juga kepada petugas kesehatan dan pengunjung yang tertular pada saat berada di dalam lingkungan fasilitas pelayanan kesehatan. ${ }^{2}$

Pencegahan dan pengendalian infeksi di rumah sakit (PPIRS) sangat penting karena menggambarkan mutu pelayanan rumah sakit juga untuk melindungi pasien, petugas, pengunjung dan keluarga dari resiko tertularnya infeksi. ${ }^{3}$ Infeksi yang terjadi di rumah sakit tidak saja dapat dikendalikan tetapi juga dapat dicegah dengan melakukan langkah-langkah yang sesuai dengan prosedur dan pedoman yang berlaku. ${ }^{4}$

Berdasarkan hasil survei yang dilakukan oleh Departemen Kesehatan RI bersama World Health Organization (WHO) ke berbagai rumah sakit di Propinsi/Kabupaten/Kota disimpulkan bahwa Komite Pencegahan dan Pengendalian Infeksi di Rumah Sakit (KPPIRS)/Tim PPIRS selama ini belum berfungsi optimal sebagaimana yang diharapkan. ${ }^{5}$ Penelitian juga menunjukkan bahwa anggota Komite/Tim PPI belum memahami dengan baik tugas, kewenangan, serta tanggung jawab yang harus dilaksanakan dalam lingkup pencegahan dan pengendalian infeksi di rumah sakit. ${ }^{6}$

World Health Organization (WHO) menetapkan protokol untuk menilai kejadian infeksi nosokomial yang terjadi di rumah sakit di dunia, diantaranya adalah menjadikan tingkat kejadian infeksi nosokomial sebagai aspek yang dinilai dalam standarisasi fasilitas kesehatan dan sistem surveilans. Sistem surveilans bertujuan untuk mengetahui insidensi dan distribusi infeksi nosokomial sehingga pada akhirnya fasilitas kesehatan tersebut dapat mengendalikan kejadian infeksi nosokomial. Dengan mengamati faktor-faktor risiko dan karakteristik pasien, tenaga medis dalam suatu fasilitas kesehatan dapat memperkirakan pasien yang rentan terpapar infeksi nosokomial sehingga pencegahan dapat dilakukan dan kondisi yang fatal dapat dihindari. $^{7}$
Penilaian mutu pelayanan dalam pencegahan dan pengendalian infeksi rumah sakit ditetapkan indikator mutu yaitu ketaatan dalam melakukan hand hygiene serta pelaporan kebijakan infeksi rumah sakit atau hasil surveilans HAl's di ruang rawat inap.

Pada studi pendahuluan yang dilakukan di RSU $X$ ditemukan peningkatan trend angka BOR (Bed Occupancy Rate) dengan jumlah tempat tidur (TT) saat ini sebanyak 55 buah tempat tidur. Mulai padatnya pemakaian tempat tidur rawat inap menyebabkan kunjungan pasien dan keluarga meningkat sebagai potensi terjadinya infeksi nosokomial di rumah sakit. Kegiatan pencatatan dan pelaporan infeksi nosokomial atau surveilans di rumah sakit baru berjalan dua bulan yaitu bulan November dan Desember 2017 yang dilakukan oleh IPCN. Dan dari data pendidikan dan pelatihan tim PPI yang ada di RSU X masih minimnya pelatihan untuk Tim PPI di RSU X, karena petugas IPCN belum bersertifikat walaupun sudah mendapatkan pelatihan PPI dasar. Petugas lainpun masih minim mendapatkan pelatihan PPI dasar dimana pelatihan PPI dasar di RSU $X$ pernah diberikan secara In House Training oleh petugas Infection Prevention Control Nurse (IPCN), namun hanya diikuti oleh sedikit petugas RSU X.

Di RSU $X$ sendiri pelaksanaan program pencegahan dan pengendalian Infeksi baru mulai terlaksana pada tahun 2017 dan masih kurang berperannya tim PPI dalam melaksanakan fungsi dan tugasnya sesuai pedoman pelaksanaan PPI yang ada di RSU.

Peningkatan mutu pelayanan kepada pasien, program PPI diprioritaskan oleh manajemen RSU X. Upaya yang dilakukan dengan membentuk Tim PPI, mengangkat tenaga IPCN yang purna waktu (full time) sebanyak satu orang. Adanya IPCN yang purna waktu tersebut sangat membantu fungsi pengawasan terhadap kinerja Infection Prevention Control Link Nurse (IPCLN) terutama yang berkaitan dengan tugas surveilans infeksi nosokomial dengan mendesain, melaksanakan, memonitor dan mengevaluasi surveilans infeksi yang terjadi rumah sakit. IPCLN adalah perawat pelaksana harian atau penghubung dengan IPCN dari tiap unit rawat inap/unit pelayanan. ${ }^{8}$ 
Tugas IPCN yang berkaitan dengan supervisi yaitu mengunjungi ruangan setiap hari untuk memonitor kejadian infeksi yang terjadi di lingkungan kerjanya, memonitor pelaksanaan PPI, penerapan SPO dan kewaspadaan isolasi kepada semua karyawan. Tujuan pokok supervisi ialah menjamin pelaksanaan berbagai kegiatan yang telah direncanakan secara benar dan tepat, dalam arti lebih efektif dan efisien, sehingga tujuan yang telah ditetapkan organisasi dapat dicapai dengan memuaskan. ${ }^{9}$ Di RSU X sendiri kegiatan pencegahan dan pengendalian infeksi yang dilaksanakan oleh IPCLN sebagai penghubung antara IPCN dan tenaga keperawatan di ruangan rawat inap dalam hal penyampaian hasil surveilans infeksi nosokomial di rumah sakit seringkali tidak berjalan sebagaimana mestinya sesuai petunjuk pedoman pelaksanaan program pencegahan dan pengendalian infeksi di rumah sakit.

\section{KASUS}

\section{Struktur Organisasi}

Setiap rumah sakit dan fasilitas pelayanan kesehatan lainnya harus melaksanakan PPI. ${ }^{2}$ Direktur Rumah Sakit dan Fasiltas Pelayanan Kesehatan lainnya membentuk Komite PPI dan Tim PPI dibawah koordinator Direktur. Di RSU X sudah ada Komite dan Tim PPI dimana Komite PPI terdiri dari ketua, sekretaris dan anggota yang merupakan perwakilan dari unit-unit yang berkaitan dengan PPI. Tim PPI terdiri, sekretaris Infection Prevention Control Nurse (IPCN), dan anggota Infection Prevention Control Link Nurse (IPCLN). Namun Komite ini belum dilegalkan karena belum ada SK yang ditandatangani oleh Direktur RSU X.

\section{Rawat Jalan}

Pada alur kegiatan pada rawat jalan yang terdapat pada RSU $X$ titik fokus pelaksanaan program pencegahan dan pengendalian infeksi berada pada ruangan poliklinik umum dan poliklinik spesialis, dimana kepatuhan petugas terhadap kebersihan tangan masih rendah dan data surveilans Infeksi Daerah Operasi juga belum optimal.

\section{Instalasi Gawat Darurat (IGD)}

Pada alur pelayanan IGD (Instalasi Gawat Darurat) pasien datang ke IGD akan dilakukan pemeriksaan triase, apakah pasien gawat darurat, gawat tidak darurat atau tidak gawat tidak darurat. Pasien yang gawat darurat, akan dilakukan resusitasi dan stabilisasi. Setelah dilakukan resusitasi dan stabilisasi, pasien akan mendapatkan pemeriksaan penunjang jika dibutuhkan. Jika membutuhkan tindakan operasi, segera dioperasi. Jika perlu dirujuk, segera dirujuk, dan jika perlu rawat inap, akan dikirim ke ruangan rawat inap. Permasalah terkait pencegahan dan pengendalian infeksi pada bagian ini adalah masih rendahnya kepatuhan petugas dalam hal kebersihan tangan dan pengunaan alat pelindung diri (APD).

\section{Instalasi Laboratorium}

Tidak hanya di IGD saja kepatuhan petugas akan kebersihan tangan dan penggunaan APD yang masih kurang, di Instalasi Laboratoriumpun juga masih rendah. Kepatuhan petugas dalam melakukan kebersihan tangan, tindakan aseptik antiseptik dan penggunaan sarung tangan belum optimal.

\section{Surveilans Infeksi Saluran Kemih, Phlebitis dan Dekubitus}

Infection Prevention Control Nurse (IPCN) mempunyai peran yang sangat penting didalam pelaksanaan surveilans Infeksi Saluran Kemih, Phlebitis, Dekubitus dalam program Pencegahan dan Pengendalian Infeksi yang ada di rumah sakit.

IPCN menyerahkan blanko surveilans kepada Infection Prevention Control Link Nurse (IPCLN) ruangan. IPCLN dibantu petugas pelaksana akan mendata setiap pasien yang berisiko (pasien yang dipasang kateter urin, infus, panflon, dan tirah baring lebih dari 48 jam). Jika terdapat infeksi, IPCLN ataupun petugas pelaksana yang menemukan kejadian tersebut, membuat kejadian infeksi di blanko surveilans. Setiap bulan, IPCLN akan menyerahkan laporan surveilans kepada IPCN. IPCN akan melakukan analisis terhadap laporan tersebut, dan membuat laporan infeksi RSU bulanan serta membuat 
rencana tindak lanjut. Laporan diserahkan kepada ketua komite PPIRS,. Setelah ditelaah oleh ketua komite, akan diteruskan kepada direktur RSU. Proses ini belum berjalan secara optimal di RSU X.

Pada tahun 2017 surveilans kejadian infeksi baru dimulai pada bulan November tahun 2017 dengan hasil sebagai berikut:

Tabel 1. Angka surveilans infeksi saluran kemih, plebitis dan decubitus bulan November sampai Desember 2017

\begin{tabular}{cccccc}
\hline No & $\begin{array}{c}\text { Hasil } \\
\text { Surveilan }\end{array}$ & \multicolumn{2}{c}{ November } & \multicolumn{2}{c}{ Desember } \\
& Kejadian & Infeksi & Kejadian & Infeksi \\
\hline 1 & $\begin{array}{c}\text { Tusukan } \\
\text { Jarum infus } \\
\text { Urine }\end{array}$ & 286 & 40 & 400 & 75 \\
2 & 15 & 0 & 41 & 0 \\
3 & $\begin{array}{c}\text { Bateter/ISK } \\
\text { Bedrest/ } \\
\text { Decubitus }\end{array}$ & 0 & 0 & 0 & 0 \\
\hline Sumber: Laporan Surveilans RSUX
\end{tabular}

\section{Surveilans Infeksi Daerah Operasi}

Di RSU X masih terdapat petugas pelaksana yang tidak mengisi pasien yang berisiko ke dalam blanko surveilans. Laporan malah dikerjakan langsung oleh IPCN. Petugas yang menemukan HAls masih ada yang tidak menuliskan, sehingga IPCLN kesulitan dalam melengkapi data tersebut. IPCLN bekerja rangkap sebagai pelaksana sehingga kesulitan dalam membuat pelaporan kejadian infeksi, jika tidak ditemukan didalam shift nya, IPCLN akan kesulitan mencari data infeksi. Ini berakibat, data surveilans menjadi bias. IPCLN kurang optimal dalam pelaporan kasus infeksi kepada IPCN.

Pada kegiatan surveilans Infeksi Daerah Operasi seharusnya IPCN menyerahkan blanko surveilans kepada IPCLN Instalasi Bedah Sentral (IBS). IPCLN di Instalasi Bedah Sentral (IBS) akan mendata setiap pasien yang berisiko (pasien yang dilakukan operasi). Setiap bulan, IPCLN IBS akan menyerahkan blanko kepada IPCN. IPCN juga menyerahkan blanko kepada IPCLN Rawat Jalan, karena lini pertama yang menemukan kasus IDO adalah petugas rawat jalan, ketika pasien post operasi melakukan kontrol ulang luka operasi. Setiap ditemukan infeksi oleh petugas pelaksana, akan dituliskan di blanko surveilans. Blanko surveilans akan diberikan setiap bulan kepada IPCN.

IPCN setelah mendapatkan blanko surveilans, IPCN akan melakukan crosscheck data dengan blanko yang dimiliki IPCLN IBS. IPCN akan melakukan analisis terhadap laporan tersebut, dan membuat laporan infeksi RSU bulanan serta membuat rencana tindak lanjut. Laporan seharusnya diserahkan kepada ketua komite PPIRS. Setelah ditelaah oleh ketua komite, akan diteruskan kepada direktur RSU.

Di RSU X pada tahun 2017 (hasil surveilan bulan November dan Desember 2017), kejadian Infeksi Daerah Operasi (IDO) pada operasi bedah ditemukan 3,63 \% kasus IDO ditemukan pada operasi kebidanan, bedah umum, bedah onkologi dan bedah digestif. Kondisi ini perlu ditelaah lebih lanjut, karena IDO dapat ditegakan apabila dokter yang bersangkutan menyatakan bahwa hal tersebut adalah IDO. Masih kurangnya monitoring IPCN untuk pengisian surveilans. Belum ada kebijakan, untuk menelaah kasus IDO dalam kurun waktu tertentu.Karena IPCLN tidak selalu ikut dan mengetahui pasien yang di operasi, sehingga saat ini IPCLN mengisi data surveilans berdasarkan status rekam medis, bahkan ada risiko data tidak terisi secara lengkap. Kondisi ini dikarenakan, tidak ada petugas yang ikut operasi (runner) yang membantu mengisi blanko surveilans supaya data lebih valid.

\section{Tata Kelola Limbah}

Pada tata kelola limbah cair di RSU X ini sudah berjalan baik, pemeriksaan terhadap baku limbah dilakukan setiap 6 (enam) bulan sekali. Untuk pelaksanaan pengelolaan limbah padat belum berjalan optimal dimana untuk pemisahan sampah infeksius dan non infeksius masih belum berjalan sesuai aturan penatalaksanaan PPI, masih ada sampah infeksius di buang ke dalam sampah non infeksius oleh petugas rumah sakit. Untuk penghancuran sampah infeksius rumah sakit bekerjasama dengan pihak ketiga, dan sementara itu dilakukan penyimpanan sampah B3 di tempat sementara

\section{Luka Tusuk jarum}

Petugas mengalami luka tusuk jarum disaat menjalani tugas merupakan salah satu resiko petugas 
dalam menjalankan tugasnya, sehingga jika hal ini terjadi maka harus ada alur kejadian tertusuk jarum (kepmenkes) yang dapat kita pedomani, seperti terlihat pada gambar berikut ini:

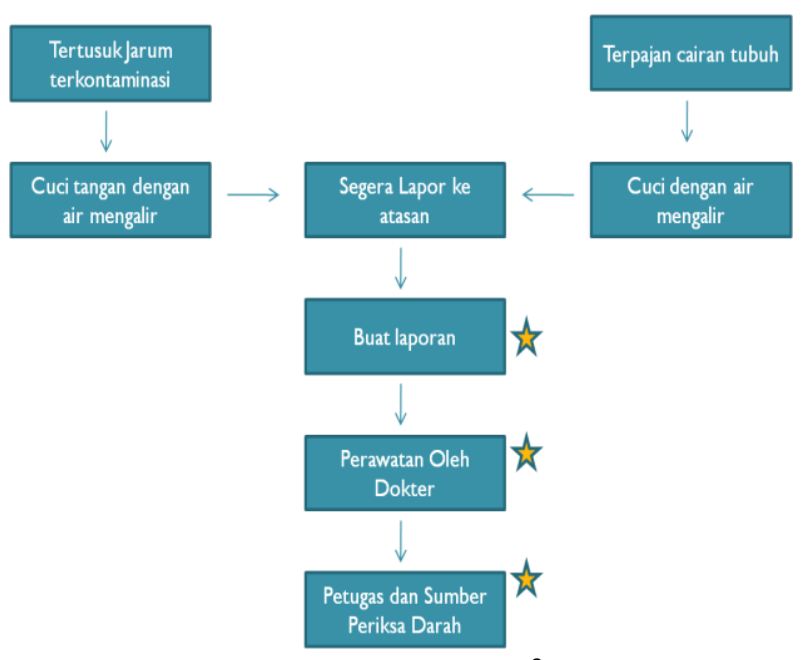

Gambar 1. Alur Luka Tusuk Jarum²

Pada saat dilaksanakannya studi kasus ini Standar Operasional Prosedur tentang kejadian luka tusuk jarum pada petugas di RSU X ini belum tersedia, anggaran khusus untuk kejadian tersebut juga belum tersedia. Terlihat pada gambar diatas bahwa setelah adanya kejadian harus dibuatkan laporan, dilakukan perawatan dan petugas serta sumber harus dilakukan pemeriksaan darah. Namun langkah-langkah tersebut belum dituangkan menjadi standar operasional prosedur sebagai tatalaksana kejadian luka tusuk jarum selama melakukan kegiatan pelayanan di rumah sakit.

Dari hasil wawancara dengan IPCN, IPCLN dan, Kepala Ruangan, beberapa poin penting hasil wawancara, sebagai berikut;

a. Secara fungsional organisasi komite pencegahan dan pengendalian infeksi rumah sakit berada dibawah direktur rumah sakit. Ketua komite sekarang adalah seorang dokter spesialis, tetapi SK penetapan masih dalam proses. Komite terdiri dari beberapa orang dari berbagai disiplin ilmu. Komite ini mempunyai 1 orang IPCN purna waktu yang merangkap sebagai Komite keperawatan, sudah mendapatkan pendidikan dan pelatihan infeksi rumah sakit dasar dan belum mendapatkan pelatihan Infection
Prevention Control Nurse (IPCN). IPCN di RSUX sudah purna waktu di PPIRS, tetapi masih memiliki tugas-tugas tambahan sebagai ketua pokja PPI danketua komite keperawatan. IPCN dibantu oleh seorang IPCLN (Infection Pervention and Control Nurse) ditiap - tiap ruang rawat inap yang sudah mendapatkan pelatihan pencegahan dan pengendalian infeksi rumah sakit walaupun hanya inhouse training oleh IPCN. Saat ini, komite PPI masih dalam proses melengkapi dokumen. Secara umum, komite PPIRS belum optimal.

b. Proses edukasi sudah dilakukan oleh IPCN kepada karyawan di RSU, tetapi belum berkesinambungan. Karyawan yang sudah mendapatkan pelatihan Pencegahan dan Pengendalian Infeksi Dasar dari Perhimpunan Pengendalian Infeksi (Perdalin) masih minim sekali (Ketua Komite dan IPCN). Sisanya mendapatkan inhouse training yang dilakukan oleh IPCN.

c. Perilaku petugas menerapkan PPI masih rendah. Kewaspadaan isolasi belum berjalan secara optimal. Kepatuhan kebersihan tangan petugas masih sangat rendah, dan belum pernah dilakukan audit kepatuhan mencuci tangan tsb.

d. Banyak petugas mengatakan bahwa mereka belum pernah mendapatkan pelatihan tentang Pencegahan dan pengendalian infeksi

e. Dalam memelihara kesehatan lingkungan, keterlibatan Komite PPI dengan cleaning service (CS) masih belum optimal.

f. Masih ada ruangan yang belum memiliki fasilitas hand wash dan hand rub seperti Laboratorium dan ruang radiologi

g. Masih ada petugas yang belum mendapatkan APD sesuai standar dalam melaksamakan tugasnya, seperti Gizi, radiologi, IGD dan ruangan lainnya

h. RSU X masih belum melibatkan Komite PPI dalam renovasi bangunan. Ketika RSU akan melakukan renovasi, komite PPI sebaiknya dilibatkan untuk membuat Infection Control and Risk Asessment (ICRA) renovasi, dan membuat rekomendasi dalam upaya pencegahan infeksi selama renovasi. 
i. Surveilans masih belum berjalan optimal, karena IPCLN belum bekerja optimal dan IPCLN pun belum pernah mendapatkan pelatihan dasar PPI

Dari penjelasan hasil observasi dan wawancara diatas maka dapat disimpulkan beberapa permasalahan PPIRS yaitu :

a. Perilaku petugas dalam menerapkan PPI masih rendah.

b. Belum adanya pelatihan PPI dasar untuk petugas rumah sakit

c. IPCN belum mendapatkan pelatihan IPCN dasar sehingga belum kompeten dalam melaksanakan tupoksinya begitu juga dengan IPCLN belum mendapatkan pelatihan PPI dasar

d. Masih kurangnya monitoring dan evaluasi pelaksanaan PPI oleh Tim PPI terutama IPCN dan IPCLN

e. kepatuhan petugas akan kebersihan tangan masih rendah

f. Belum melakukan kewaspadaan isolasi secara optimal.

g. Peran komite PPI dan tim PPI belum optimal.

h. Surveilans belum optimal.

i. Pencatatan dan pelaporan masih dalam bentuk manual j. Kebersihan lingkungan belum optimal.

k. Dokumen PPI masih berupa draf

I. Fasilitas dan jumlah hand wash dan hand rub yang belum mencukupi dan belum terdistribusi secara rata

m. Fasilitas dan jumlah APD yang belum cukup dan terdistribusi rata

n. Fisik bangunan yang sesuai standar PPI RS masih minimal, seperti ruang isolasi untuk penyakit menular tidak ada

o. Koordinasi antar unit terkait rendah.

p. Alokasi dana PPI yag rinci belum ada.

\section{PEMBAHASAN}

Berdasarkan identifikasi masalah terhadap gambaran pelaksanaan program pencegahan dan pengendalian infeksi di RSU X maka langkah selanjutnya adalah menentukan alternative dan prioritas masalah. Hal ini dilakukan dengan mengunakan metode efektivitasefisiensi

M : Magnitut yaitu besarnya masalah yang dapat diatasi

I : Important pentingnya jalan keluar untuk menyelesaikan masalah

V : Vulnerability, Sensitivitas (ketepatan jalan keluar untuk masalah )

C. : Cost, Efisiensi biaya yang dikeluarkan 
Tabel 2. Prioritas pemecahan masalah

\begin{tabular}{|c|c|c|c|c|c|c|c|}
\hline No & Alternatif & $\mathbf{M}$ & I & V & (Efesiensi) C & Skor & Prioritas \\
\hline 1 & $\begin{array}{l}\text { Melakukan inhouse training yang berkesinambungan ke semua lini } \\
\text { pegawai RSU X mengenai tujuan dan manfaat PPI serta mengenai } \\
\text { kebijakan/SOP/Pedoman/panduan PPI yang telah disyahkan }\end{array}$ & 5 & 5 & 4 & 2 & 50 & 8 \\
\hline 2 & $\begin{array}{l}\text { IPCN setiap hari melakukan edukasi dan monitoring terhadap } \\
\text { pelaksanaan program PPI di lapangan }\end{array}$ & 4 & 4 & 4 & 1 & 64 & 4 \\
\hline 3 & $\begin{array}{l}\text { Memberikan kesempatan IPCN dan IPCLN untuk mengikuti } \\
\text { pelatihan IPCN dan PPI dasar untuk IPCLN sehingga IPCN dan } \\
\text { IPCLN bisa melaksanakan tugas sebagai IPCN dan IPCLN dengan } \\
\text { profesional dan kompeten }\end{array}$ & 5 & 4 & 4 & 1 & 80 & 2 \\
\hline 4 & $\begin{array}{l}\text { Membuat Kebijakan/ SPO/ Pedoman/ Panduan PPI yang telah } \\
\text { disahkan untuk dipergunakan di lingkungan RS dalam kurun waktu } 1 \\
\text { bulan. (mensyahkan dokumen yang sudah dalam bentuk draf) }\end{array}$ & 5 & 5 & 5 & 2 & 62,5 & 5 \\
\hline 5 & $\begin{array}{l}\text { Menyediakan fasilitas hand wash dan hand rub serta alat pelindung } \\
\text { diri dan mendistribusikannya secara rata sesuai standar }\end{array}$ & 4 & 4 & 4 & 2 & 32 & 12 \\
\hline 6 & $\begin{array}{l}\text { Memberdayakan IPCLN dalam pencatatan dan pelaporan angka } \\
\text { terkait infeksi nosokomial dan kasus/wabah }\end{array}$ & 4 & 4 & 3 & 1 & 48 & 9 \\
\hline 7 & $\begin{array}{l}\text { Melakukan penyuluhan rutin untuk pasien, keluarga dan pengunjung } \\
1 \mathrm{x} \text { sebulan }\end{array}$ & 4 & 3 & 3 & 1 & 36 & 10 \\
\hline 8 & $\begin{array}{l}\text { Menyediakan media penyuluhan audio visual yang ada di ruang } \\
\text { tunggu tentang program PPI untuk pasien, keluarga dan pengunjung } \\
\text { terutama tentang cuci tangan dan etika batuk }\end{array}$ & 4 & 4 & 3 & 2 & 24 & 14 \\
\hline 9 & $\begin{array}{l}\text { Melakukan rapat koordinasi yang berkesinambungan } 1 \times \text { sebulan } \\
\text { yang dihadiri oleh direktur dan unit-unit yang terkait dengan PPI } \\
\text { untuk membahas hambatan dan rencana tindak lanjut }\end{array}$ & 5 & 5 & 4 & 1 & 100 & 1 \\
\hline 10 & $\begin{array}{l}\text { Ketua Komite, IPCN dan IPCLN terlibat aktif dalam membuat } \\
\text { rencana kerja komite PPIRS secara terinci setiap tahunnya }\end{array}$ & 5 & 4 & 3 & 1 & 60 & 6 \\
\hline 11 & $\begin{array}{l}\text { Menghitung kebutuhan terkait PPI secara terinci oleh instalasi yanh } \\
\text { membutuhkan, dipandu oleh IPCN sehingga sesuai standar. Dan } \\
\text { membuat kebutuhan secara rinci pada dokumen anggaran }\end{array}$ & 5 & 4 & 3 & 1 & 60 & 7 \\
\hline 12 & $\begin{array}{l}\text { IPCN melakukan audit terhadap kewaspadaan standar } 1 \times 3 \text { bulan } \\
\text { dan mengumumkan hasil audit ketika rapat koordinasi atau rapat } \\
\text { rutin bulanan }\end{array}$ & 5 & 4 & 4 & 1 & 80 & 3 \\
\hline 13 & $\begin{array}{l}\text { Menyediakan ruangan khusus isolasi untuk pasien dengan penyakit } \\
\text { menular dan pasien dengan imunitas rendah }\end{array}$ & 5 & 4 & 4 & 3 & 26,6 & 13 \\
\hline 14 & $\begin{array}{l}\text { Melibatkan komite PPI dalam rangka rekomendasi penempatan } \\
\text { pasien }\end{array}$ & 4 & 3 & 3 & 1 & 36 & 11 \\
\hline
\end{tabular}


Berdasarkan Tabel 2 yang menjadi prioritas alternatif pemecahan masalah adalah:

a. Melakukan rapat koordinasi yang berkesinambungan $1 \times$ sebulan yang dihadiri oleh direktur dan unit-unit yang terkait dengan PPI untuk membahas hambatan dan rencana tindak lanjut

b. Memberikan kesempatan IPCN dan IPCLN untuk mengikuti pelatihan IPCN dan PPI dasar untuk IPCLN sehingga IPCN dan IPCLN bisa melaksanakan tugas sebagai IPCN dan IPCLN dengan profesional dan kompeten

c. IPCN melakukan audit terhadap kewaspadaan standar 1 × 3 bulan dan mengumumkan hasil audit ketika rapat koordinasi atau rapat rutin bulanan

d. IPCN setiap hari melakukan edukasi dan monitoring terhadap pelaksanaan program PPI di lapangan

e. Membuat Kebijakan/ SPO/ Pedoman/ Panduan PPI yang telah disahkan untuk dipergunakan di lingkungan RS dalam kurun waktu 1 bulan. (mensyahkan dokumen yang sudah dalam bentuk draf)

f. Ketua Komite, IPCN dan IPCLN terlibat aktif dalam membuat rencana kerja komite PPIRS secara terinci setiap tahunnya

g. Menghitung kebutuhan terkait PPI secara terinci oleh instalasi yanh membutuhkan, dipandu oleh IPCN sehingga sesuai standar. Dan membuat kebutuhan secara rinci pada dokumen anggaran

h. Melakukan inhouse training yang berkesinambungan ke semua lini pegawai RSU X mengenai tujuan dan manfaat PPI serta mengenai kebijakan/SOP/Pedoman/panduan PPI yang telah disyahkan

i. Memberdayakan IPCLN dalam pencatatan dan pelaporan angka terkait infeksi nosokomial dan kasus/wabah

j. Melakukan penyuluhan rutin untuk pasien, keluarga dan pengunjung 1 x sebulan

k. Melibatkan komite PPI dalam rangka rekomendasi penempatan pasien

I. Menyediakan fasilitas hand wash dan hand rub serta alat pelindung diri dan mendistribusikannya secara rata sesuai standar m. Menyediakan ruangan khusus isolasi untuk pasien dengan penyakit menular dan pasien dengan imunitas rendah

n. Menyediakan media penyuluhan audio visual yang ada di ruang tunggu tentang program PPI untuk pasien, keluarga dan pengunjung terutama tentang cuci tangan dan etika batuk

Dari empat belas alternatif prioritas pemecahan masalah maka perlu dirumuskan Plan of Action (PoA) untuk optimalisasi program PPI rumah sakit. Kegiatan yang telah dituangkan dalam bentuk plan of action selanjutnya perlu dilakukan monitoring dan evaluasi dalam menilai kinerja dari program pelaksanaan pencegahan dan pengendalian infeksi di rumah sakit.

\section{SIMPULAN}

Pencegahan dan Pengendalian Infeksi (PPI) merupakan salah satu indikator mutu yang perlu ditingkatkan di RSU X. Berdasarkan pengamatan dan wawancara dengan petugas serta komite PPIRS RSU $X$ terhadap alur prosedur program PPI dan kegiatan pelaksanaan terkait program PPI belum berjalan optimal dan belum sesuai dengan peraturan yang berlaku yaitu Permenkes no 27 tahun 2017 di RSU X Kota $Y$

\section{SARAN}

Manajemen RS: Memberikan dukungan yang optimal untuk PPIRS, mengurangi tugas tambahan IPCN selain di PPI sehingga IPCN lebih fokus di PPI, membuat kebijakan koordinasi PPI dengan unit terkait.

Komite PPI: Melakukan koordinasi yang optimal antara PPI dengan unit terkait, melakukan proses monitoring dan evaluasi.

IPCN: Mengikutsertakan IPCN untuk pelatihan IPCN sehingga IPCN Aktif melakukan edukasi, monitoring serta evaluasi yang dilakukan secara berkesinambungan untuk mengubah perilaku petugas $\mathrm{RS}$ secara profesional dan kompeten.

\section{UCAPAN TERIMAKASIH}

Terimakasih kepada Direktur RSU X beserta staf, Komite PPIRS RSU $X$ beserta timnya dan juga semua pihak yang terlibat dalam memotivasi, bimbingan dan bantuan pada studi kasus ini. 


\section{DAFTAR PUSTAKA}

1. Dawson SJ. The Role of the infection control link nurse. Journal of Hospital Infection. 2003;54:251-7.

2. Kementerian Kesehatan RI. Keputusan menteri kesehatan RI. pedoman pencegahan dan pengendalian infeksi di fasilitas kesehatan. Jakarta: Kementerian Kesehatan Rl; 2017.

3. Alvarado CJ. The science of hand hygiene: a self study monograph. USA: University of Wisconsin Medical and School and Sci-Health Communication. 2017;21:231-3.

4. Departemen Kesehatan RI. Petunjuk Praktis Surveilans Infeksi di Rumah Sakit. Jakarta: Departemen Kesehatan RI; 2010.

5. World Health Organization (WHO). Interim guideline infection prevention and control of epidemic and pandemic prone acute respiratory diseases in health care. Geneva: WHO; 2007.

6. Molina VF. Analisis pelaksanaan program pencegahan dan pengendalian infeksi nosokomial di Rumkital Dr. Mintohardjo Jakarta tahun 2012 [tesis]. Depok: Program Pascasarjana Universitas Indonesia; 2012.hlm.71-2.

7. World Health Organization (WHO). Prevention of hospital acquired infections. Geneva: WHO; 2002.

8. Direktur Jendral Bina Pelayanan Medik Depkes dan Perdalin. Pedoman manajerial pencegahan dan pengendalian infeksi di rumah sakit dan fasilitas pelayanan kesehatan lainnya. Jakarta: Depkes RI; 2008.

9. Suarli S, Bachtiar Y. Manajemen keperawatan. Jakarta: Erlangga; 2009.hlm.35-7. 